\title{
Postpartum Health of Employed Mothers 5 Weeks After Childbirth
}

\author{
Pat McGovern, $\mathrm{PbD}{ }^{1}$ \\ Bryan Dowd, $P b D^{1}$ \\ Dwenda Gjerdingen, $M D^{2}$ \\ Cyntbia R. Gross, $P b D^{3}$ \\ Sally Kenney, $P b D^{4}$ \\ Laurie Ukestad, MS ${ }^{1}$ \\ David McCaffrey ${ }^{1}$ \\ Ulf Lundberg, $P b D^{5}$ \\ ${ }^{1}$ School of Public Health, University of \\ Minnesota, Minneapolis, Minn \\ ${ }^{2}$ Medical School, University of Minnesota, \\ Minneapolis, Minn \\ ${ }^{3}$ College of Pharmacy and School of Nursing, \\ University of Minnesota, Minneapolis, Minn \\ ${ }^{4}$ Hubert H. Humphrey Institute of Public \\ Affairs, University of Minnesota, Minneapolis, \\ Minn \\ ${ }^{5}$ Department of Psychology, Stockholm \\ University, Stockholm, Sweden
}

\begin{abstract}
PURPOSE Most new mothers return to work soon after childbirth. A need exists to reexamine the definition of postpartum health and evaluate employed women's recovery from childbirth in association with such factors as delivery type and breastfeeding.

METHODS Using a prospective cohort design, we recruited Minnesota women into the study while they were hospitalized for childbirth in 2001. Telephone interviews were conducted 5 weeks postpartum. Eligible women were 18 years or older, employed, and spoke English. Multivariate models using 2-stage least squares were used to estimate factors associated with physical and mental health and postpartum symptoms.
\end{abstract}

RESULTS A total of 817 women were enrolled (71\% response) in the study; 716 women completed interviews at 5 weeks postpartum. On average, women reported 6 postpartum symptoms, most frequently fatigue (64\%), breast discomfort (60\%), and decreased desire for sex (52\%). Findings showed that cesarean (vs vaginal) deliveries were associated with significantly worse physical function, role limitations, and vitality. Multivariate findings showed that the effect of delivery type on physical health was moderately large $(\beta=-5.96 ; P=<.01)$, and breastfeeding was associated with an increased frequency of postpartum symptoms $(\beta=4.63 ; P=.01)$.

CONCLUSIONS These mothers experienced several childbirth-related symptoms at 5 weeks postpartum, indicating a need for ongoing rest and recovery. Health concerns were greater for women who were breastfeeding and for those whose babies were delivered by cesarean section, suggesting a need for greater support for these women and a reassessment by the medical community of the progressively growing practice of cesarean deliveries.

Ann Fam Med 2006;4:159-167. DOI: 10.1370/afm.519.

\section{INTRODUCTION}

$\mathrm{T}$

The participation of American women in the labor force during the last 20 years has changed most dramatically for mothers of infants. In 2003 their labor force participation rate was at $54 \%,{ }^{1}$ dipping slightly from a record high of $58 \%$ in 1998 , but markedly higher than $31 \%$ in $1966 .{ }^{2}$ Many of today's mothers are established in the marketplace before starting their families and remain employed during their child's infancy by taking a family or medical leave. ${ }^{3,4}$ Among first-time mothers employed during pregnancy and giving birth in the United States between 1991 and $1994,13 \%$ had returned to work by 1 month after childbirth, increasing to $30 \%$ by 2 months, and $41 \%$ by 3 months, for a total of $76 \%$ returning within the first year after childbirth. ${ }^{4}$ With many new mothers returning to work soon after childbirth, a need exists to reexamine and broaden the definition of postpartum health, particularly for employed women.

Traditionally, the medical perspective of the postpartum period refers to the time after childbirth that is required for the reproductive organs to return to their nonpregnant state, a process of about 6 weeks. ${ }^{5}$ For physicians this time is often perceived as one that requires little assistance other 
than the single postpartum visit recommended at 4 to 6 weeks after delivery. Yet findings from longitudinal studies suggest that recovery from childbirth involves more than the healing of reproductive organs. Most women contend with several minor to moderate discomforts for weeks (eg, fatigue, breast soreness, cesarean section or episiotomy discomfort, constipation, hemorrhoids, and sexual concerns), ${ }^{5-10}$ and some face serious problems, such as depression, ${ }^{11-14}$ that may limit daily activities for months. ${ }^{15}$

Although postpartum recovery is likely affected by such common factors as cesarean delivery or breastfeeding, few studies have examined the association of these variables with postpartum health.

Cesarean deliveries reached a record high of $26 \%$ of all US births in 2002, increasing from $21 \%$ in $1996 .{ }^{16}$ The rise in the cesarean section delivery rate is primarily a result of an increase in primary cesarean sections ${ }^{16}$ and a steep decline in vaginal births after a previous cesarean delivery. ${ }^{17}$ Whereas cesarean deliveries produce higher rates of postpartum infections, ${ }^{18,19}$ vaginal deliveries are associated with increased discomfort with sexual intercourse, ${ }^{5,7,20}$ fecal incontinence, ${ }^{21}$ hemorrhoids, ${ }^{5,7}$ and urinary stress incontinence. ${ }^{7,22}$ There is little information, however, comparing general mental and physical health and function in women by delivery type beyond the immediate postpartum period.

Although Healthy People 2010 initiatives promote a goal of $75 \%$ breastfeeding initiation through the early postpartum period, ${ }^{23}$ national estimates show that $68 \%$ of children were breastfed to any extent at 7 days declining to $52 \%$ at 3 months. ${ }^{24}$ Benefits of breastfeeding include enhanced infant nutrition and immunity, more rapid uterine involution, easier loss of pregnancy weight, and reduced risks of breast cancer and osteoporosis. ${ }^{25,26}$ Breastfeeding, however, may also cause problems, including plugged milk ducts, nipple soreness or cracking, and mastitis, ${ }^{27,28}$ which may affect maternal vitality on a daily basis. Fewer women who return to work full-time initiate and continue breastfeeding compared with those who return part-time. ${ }^{29,30}$

With many new mothers returning to work soon after childbirth, a need exists to investigate factors that may affect their well-being. This article extends previous research by examining the effect of delivery type and breastfeeding on women's health at 5 weeks postpartum in a sample of employed women, some of whom have already returned to work.

\section{METHODS}

\section{Theory}

The theory underlying this analysis is a hybrid model of health and workforce participation adapted from
Becker ${ }^{31}$ and Grossman. ${ }^{32}$ The theoretical model assumes that health is determined by genetic endowment, other "predetermined" factors, and personal choices. For example, women's postpartum health is explained not only by demographics, preconception health status, and childbirth experience, but also by choices. Mothers' choices (eg, timing of return to work, whether to breastfeed, or use of health care services) are conceptualized in the model as contributing to the production of women's health. The application of this theoretical model to the research question has implications for the study design and estimation methods.

For our purposes, women's postpartum health was modeled as a function of (1) predetermined variables that include personal, perinatal or employment factors; and (2) choice variables that include hours of work, health services used, and breastfeeding status. The inclusion of choice variables among our explanatory variables required special attention when the model was estimated.

\section{Study Design}

Using a prospective cohort study design, we selected 3 community hospitals from Minneapolis-St Paul, Minn. Given the ethnic diversity and urban/suburban locations of these hospitals, the demographics of their birth mothers were anticipated to be comparable to those of women giving birth at 41 other hospitals in the 7-county area. Two hospitals were from a private, nonprofit St Paul health care system: 1 urban, tertiary care hospital with 258 licensed beds and 1,000 annual deliveries; the other a suburban, tertiary care hospital with 184 licensed beds and 2,700 annual deliveries. The third site, located in an ethnically diverse working-class Minneapolis suburb, was a private, nonprofit 546-bed teaching hospital with 3,000 annual deliveries.

Participants were recruited from the population of women aged 18 years and older who were admitted to the hospital for childbirth between April 9, 2001, and November 19, 2001. Sample selection criteria included residing in the 7 -county area, giving birth to a single infant without serious complications, speaking English, and being employed before childbirth, and intending to return to work after childbirth.

\section{Data Collection}

A structured questionnaire was developed using measures with established reliability and validity wherever possible. Perinatal nurses conducted study enrollment in person. University research staff subsequently conducted a telephone interview using a 4 -week window for conducting the interview (ie, 4 to 8 weeks postpartum). The full interview required 45 minutes, whereas, to assess for response bias, a 10-minute mini interview 
was available for women who had quit employment or had time constraints.

All staff was extensively trained in nonbiased interviewing techniques. After receiving approval from the relevant institutional review boards, nurses reviewed women's medical charts relative to primary selection criteria and interviewed potentially eligible women regarding employment criteria and informed consent.

\section{Measures of Dependent and Independent Variables}

The dependent variables included (1) a physical component summary (PCS) score, (2) a mental component summary (MCS) score, and (3) a postpartum symptom score. The PCS and MCS were taken from the SF-12 (Version 2), a 12 -item measure of general health that is internationally recognized for its validity, reliability, and the availability of population norms. ${ }^{33}$ The general population norms for the SF-12v2 were estimated from responses to the 1998 National Survey of Functional Health Status, which includes 550,000 households representative of the US population.

Questionnaire items addressed physical function, role limitations from physical and emotional health, bodily pain, general health, social function, mental health, and vitality, which are summarized into physical and mental component scores. Because the SF-12 is standardized and norm-based, all scores above and below 50 are above and below the average, respectively, in the general US population. ${ }^{33}$ Ware et al reported that effects in the PCS and MCS can be interpreted as very large (10 points or more), moderate to large ( 5 to 10 points), or small to moderate ( 2 to 5 points). ${ }^{33}$

The 28-item postpartum symptom score was adapted from a 76-item symptoms checklist used in a previous postpartum study. ${ }^{5}$ Items were selected for this study based on their increased prevalence after childbirth (as noted in the earlier study) ${ }^{5}$ or potential association with childbirth.

The independent variables included measures of personal, perinatal, postpartum, and employment factors (Table 1). ${ }^{34-43}$

\section{Statistical Analyses}

Some of our explanatory variables were chosen by the subject (eg, hours of work). In the case of these endogenous explanatory variables, there may be unobserved variables that influence both the value of the choice variable and the subsequent maternal health outcomes, resulting in omitted variables bias (sometimes referred to as confounding bias). This potential problem was addressed through the use of instrumental variables estimation methods (in this case, 2-stage least squares or $2 \mathrm{SLS}) .{ }^{44}$ The estimated regression coefficient for any variable shows the effect of a 1-unit change in the explanatory variable on the dependent variable. For example, when the PCS score is regressed on "delivery type" and other explanatory variables, the regression coefficient for delivery type is -5.96 . Thus, the PCS score for women having a cesarean section (coded 1) vs a vaginal delivery (coded 0 ) declines approximately 6 points, a moderate to large effect.

\section{RESULTS}

\section{Generalizability}

The generalizability of the study population can be evaluated in relation to national data. The Minnesota study population was restricted to mothers 18 years of age and older, on average 29 years. The Minnesota mothers were less likely to be married $(77 \%)$ than new mothers aged 25 to 29 years nationwide $(83 \%)^{2}$ and were less likely to give birth by cesarean section $(17 \%$ vs $24 \%$, respectively). ${ }^{45}$ The Minnesota mothers were more likely to have completed high school (94\%) when compared with national data on new mothers aged 25 to 34 years ( $84 \%$ to $90 \%) .{ }^{46}$ The proportion of white and Native American mothers in the study population was comparable to that found in the national data $(78 \%$ and $1 \%$, respectively), but the study population had relatively fewer African American mothers (9\% vs 15\%) and more Asian mothers (11\% vs 5\%). ${ }^{46}$

\section{Descriptive Statistics}

Among 2,736 women giving birth at the study hospitals for the 8-month study enrollment period, 1,157 met eligibility criteria ( $42 \%$ of births). Among 1,579 ineligible women, 581 (37\%) were ineligible because of demographic or health characteristics, and 998 women (63\%) were ineligible because of employment-related criteria.

The study enrolled 817 women (response rate: $71 \%$ of eligible women). Women who refused participation stated a lack of interest or time. No significant differences between participants and refusals were found for infant birth weight, gestation, maternal age, marital status, or employment duration.

At 5 weeks postpartum (mean 4.8 weeks, SD 1 week), 716 participants ( $87.5 \%$ of enrollees) completed a full interview, 30 women $(3.5 \%)$ completed a mini interview, and 71 (9\%) could not be reached. Comparisons showed that women completing the full interview were slightly older, more likely to be white and married, and more likely to report higher household incomes relative to others (Table 2 ). Women completing the full and mini interviews, however, did not differ significantly (by $t$ test) on their mental or physical health scores at 5 weeks postpartum. 


\title{
Table 1. Measures of Independent Variables
}

\author{
Independent Variables (Coding)

\section{Personal Factors} \\ Age (years) \\ Race ( 1 = white, 0 = non-white) \\ College educated $(1$ = yes; $0=$ no) \\ Marital status ( $1=$ married; $0=$ no) \\ Primiparous ( 1 = yes; 0 = else) \\ Annual household income (\$) \\ Prenatal smoking $(1=$ yes; $0=$ no) \\ Perceived control ( $1=$ none/very little, \\ 2 = some, $3=$ a lot, $4=$ complete) \\ Social support \\ of the time to $25=$ all of the time)

\section{Perinatal Factors} \\ Chronic health problems \\ ( 1 = some problems; $0=$ none $)$ \\ Preconception health \\ (1 = poor/fair, 2 = good, \\ $3=$ very good, $4=$ excellent) \\ Prenatal mood disturbances \\ ( 1 = yes; 0 = no) \\ Labor and delivery complications \\ ( 1 = some problems; $0=$ none) \\ Cesarean delivery $(1=$ yes, $0=$ no) \\ Infant girl ( $1=$ yes, $0=$ no) \\ Colicky baby $(1=$ yes, $0=$ no)
}

(5-item scale with summary score: $5=$ none

\section{Postpartum Factors}

Breastfeeding $(1=$ yes, $0=$ no $)$

Health services used $(\$)$

Time elapsed since childbirth (days)

\section{Employment characteristics}

Employment status ( 1 = working,

$0=$ on leave from work)

Occupational classification

(blue collar/service $=1$; else $=0$; clerical $=1$;

else $=0$; professional $=$ reference)

Prenatal hours worked/week (hr)

Prenatal job stress

( 2 -item summary score of 2 = almost

never to 10 almost always)

Prenatal job satisfaction

$(1$ = very to somewhat satisfied;

$0=$ very to somewhat dissatisfied)

Prenatal supervisor support

$(1=$ strongly disagree, 2 = disagree,

$3=$ agree, $4=$ strongly agree)

* Data collected in person at enrollment in the hospital.

† Data collected by telephone at the 5-week interview.

Characteristics of women completing the full interview are displayed in Table 3. Mothers scored slightly worse than women nationally on physical health (mean 51.4 vs $52.7 ;$ SD $7.2,9.13 ; z=-3.9 ; P<.001$ )
Abstracted from the medical chart

Adapted from Census 2000 34 *

Adapted from National Health Interview Survey ${ }^{35 *}$

Adapted from National Health Interview Survey ${ }^{35 *}$

Adapted from National Health Interview Survey ${ }^{35 *}$

Adapted from National Health Interview Survey ${ }^{35 *}$

Item assessed smoking during pregnancy 36 *

"Before this pregnancy how much control did you have over the time and effort spent caring for family, doing home chores or paid work?"37*

"How often are the following kinds of support available to you, if needed: someone to: (1) confide in or talk about your problems, (2) get together with for relaxation, (3) help with daily chores if you are sick, (4) turn to for suggestions about how to handle personal problems, and (5) someone to love and make you feel wanted"38*

Presence/absence of hypertension, diabetes, cardiac disease, renal disease, asthma; abstracted from medical records

"How would you rate your health in general before this pregnancy?" item adapted from $\mathrm{SF}-12^{33 *}$

"During this pregnancy did you ever have a problem with your mood, such as feeling depressed or anxious?"11*

Presence/absence of anesthetic complications, excessive bleeding, lacerations, seizures, eclampsia, abruptio placenta or infections; abstracted from medical chart

Abstracted from medical chart

Abstracted from medical chart

Item developed and validated by investigators ${ }^{6}$ : "Has your baby had fussy, irritable behavior that lasts for at least 2 days or had colic?"†

Item developed and validated by investigators, ${ }^{6}$ "Which of the following are you feeding your baby: breast milk, formula, milk (cow or soy), other? " (Multiple response options allowed) ${ }^{\dagger}$

Measure of price-weighted volume of health care services used after hospital discharge from childbirth through 5-wk interview. Services included emergency department visits, number of hospital days, outpatient surgeries/procedures, doctor office/urgent care visits, mental health visits; the number of encounters was multiplied by the unit price/encounter using claims data for women of reproductive years from Blue Cross Blue Shield Minnesota, 2001 All costs were summed for a price-weighted volume of services used ${ }^{39}$

Computed from infant birth date and interview date

Item adapted from Cantor et al ${ }^{40 *}$

Taken from US Census ${ }^{41 \dagger}$

Average work hours past $12 \mathrm{mo}$ *

Items taken from Mardburg et $\mathrm{al}^{37}$ and validated ${ }^{6}$; "How often do you have too much to do? How often do you experience stress from your job?" *

Global job satisfaction item taken from Quinn and Staines ${ }^{42 *}$

Item adapted from Bond et $\mathrm{al}^{43}$ and validated ${ }^{6}$; assesses maternal perception of supervisor's helpfulness during pregnancy 
Table 2. Important Differences Between Women by 5-Week Interview Status

\begin{tabular}{|c|c|c|c|c|}
\hline \multirow[b]{2}{*}{ Variables } & \multicolumn{3}{|c|}{ Mean No. (SD) } & \multirow{2}{*}{$\begin{array}{l}\text { Significance of F Test } \\
\text { Using ANOVA or } t \text { Test* } \\
\text { P Value }\end{array}$} \\
\hline & $\begin{array}{l}\text { Full Interview } \\
\mathrm{n}=716\end{array}$ & $\begin{array}{l}\text { Mini Interview } \\
\mathrm{n}=30\end{array}$ & $\begin{array}{l}\text { No Interview } \\
\mathrm{n}=71\end{array}$ & \\
\hline \multicolumn{5}{|l|}{ Continuous } \\
\hline Maternal age, y & $29.9(5.30)$ & $27.2(5.8)$ & $27.9(6.1)$ & .001 \\
\hline Annual household income, $\$$ & $71,741(38,018)$ & $51,930(27,122)$ & $66,262(39,902)$ & .012 \\
\hline $\begin{array}{l}\text { Days from childbirth until } \\
5 \text {-wk interview }\end{array}$ & $33.42(6.32)$ & $42.73(11.3)$ & $\mathrm{N} / \mathrm{A}$ & $<.001$ \\
\hline Physical health (PCS) score & $51.4(7.2)$ & $49.4(11.3)$ & N/A & Not significant* \\
\hline \multirow[t]{2}{*}{ Mental health (MCS) score } & $49.6(7.9)$ & $49.4(7.6)$ & N/A & Not significant* \\
\hline & \multicolumn{3}{|c|}{ No. (\%) } & Significance of $\chi^{2}$ \\
\hline \multicolumn{5}{|l|}{ Discrete } \\
\hline White & $615(86)$ & $13(43)$ & $53(75)$ & $<.001$ \\
\hline Married & $531(74)$ & $14(47)$ & $38(54)$ & $<.001$ \\
\hline College educated & $331(46)$ & $7(23)$ & $16(23)$ & $<.001$ \\
\hline $\begin{array}{l}\text { One or more chronic health } \\
\text { problems }\end{array}$ & $116(16)$ & $10(33)$ & $15(21)$ & .040 \\
\hline \multicolumn{5}{|c|}{$\begin{array}{l}\mathrm{PCS}=\text { physical component summary of the SF-1233; MCS = mental component summary of the SF-12 } 2^{33} ; \mathrm{N} / \mathrm{A} \text { denotes that information is missing for enrolled subjects } \\
\text { given their interview status at } 5 \text { weeks postpartum. }\end{array}$} \\
\hline \multicolumn{5}{|c|}{$\begin{array}{l}\text { Note: Variables not significantly different between groups included the proportion of women who smoked while pregnant, were primiparous; experienced prenatal mood } \\
\text { problems, labor and delivery complications, cesarean deliveries; and reported prenatal prenatal job satisfaction. There were no differences between groups on the mean } \\
\text { levels of perceived control and preconception overall health and prenatal job stress. The proportion of women on leave vs returned to work at } 5 \text { weeks did not vary between } \\
\text { women completing the full interview and those completing the mini interview because of time constraints. }\end{array}$} \\
\hline \multicolumn{5}{|c|}{${ }^{*} t$ Test used to evaluate the differences in mean PCS and MCS scores between women completing the full interview and those completing the mini interview. } \\
\hline
\end{tabular}

cesarean sections reported significantly worse physical function, role limitations, vitality, and pain. Significant differences in mean scores on SF-12 subscales by delivery type (using analysis of variance), in which a higher score reflects better health, were found for physical function (54.5 for vaginal vs 48.9 for cesarean section, $P<.001$ ); physical role limitations (50.5 for vaginal vs 44.4 for cesarean section, $P<.001)$; vitality (48.0 for vaginal vs 45.19 for cesarean section, $P=.001)$; and bodily pain ( 49.8 for vaginal vs 43.3 for cesarean section, $P<.001)$.

On average, women reported 6.2 symptoms overall (SD 3.5), and 4.9 symptoms (SD 3.1) when breast symptoms were excluded. The most frequent symptom was fatigue at $63.8 \%$ (Table 4 ). On average, women reported 6.4 hours of sleep, being awakened 2.6 times per night, and $50 \%$ reported never or rarely feeling refreshed after waking in the morning.

\section{Multivariate Results}

\section{Women's Physical Health}

Results from 2SLS that revealed factors significantly associated with better postpartum physical health included better preconception health, increased perceived control, a vaginal (vs cesarean section) delivery, and more time since childbirth (Table 5). The effect of delivery type on physical health was moderate to large (approximately 6 points), whereas the effects of other variables were small.

\section{Women's Mental Health}

Factors significantly associated with better postpartum mental health included better preconception health, an absence of prenatal mood problems, having a baby girl, and more available social support (Table 5). These effects were small to moderate. The effects of delivery type and breastfeeding on mental health were not statistically significant.

\section{Women's Postpartum Symptoms}

Women's breast symptoms were excluded from the summary score because they were considered to be a consequence of breastfeeding. Fewer symptoms were significantly associated with better preconception health, an absence of prenatal moods, not having a colicky baby, and not breastfeeding (Table 5). The effect of not breastfeeding on symptoms was moderate, whereas the effects of preconception health, prenatal moods, and a colicky baby were small. Delivery type was not associated with symptoms.

Breastfeeding at 5 weeks postpartum was associated with more symptoms than not breastfeeding (6.6 vs 5.1 for all symptoms, and 5.2 vs 4.5 for symptoms other than breast-related). Breastfeeding mothers experienced significantly more fatigue, breast symptoms, back and neck pain, more constipation and hemorrhoids, sweating, and hot flashes and less desire for sex than women not breastfeeding, based on exploratory analyses conducted with $\chi^{2}$ tests (Table 6). There were 


\begin{tabular}{|c|c|}
\hline Variables & $\begin{array}{l}\text { Value } \\
\text { Mean No. (SD) }\end{array}$ \\
\hline \multicolumn{2}{|l|}{ Continuous } \\
\hline Maternal age, y & $29.9(5.30)$ \\
\hline Annual household income, $\$$ & $71,741(38,018)$ \\
\hline $\begin{array}{l}\text { Prenatal perceived control }(1=\text { little control } \\
\text { to } 4=\text { complete control) }\end{array}$ & $3.04(0.72)$ \\
\hline $\begin{array}{l}\text { Available social support (summary score } \\
5=\text { none of the time to } 25=\text { all of } \\
\text { the time) }\end{array}$ & $20.7(3.68)$ \\
\hline $\begin{array}{l}\text { Preconception health }(1=\text { poor/fair to } \\
4=\text { excellent })\end{array}$ & $3.09(0.79)$ \\
\hline Health services used, $\$$ & $191(1,119)$ \\
\hline $\begin{array}{l}\text { Days elapsed from childbirth until 5-wk } \\
\text { interview, No. }\end{array}$ & $33.42(6.32)$ \\
\hline Prenatal time worked, h/wk & $38.1(8.50)$ \\
\hline Prenatal job stress $(1=$ never to $8=$ always $)$ & $4.35(1.73)$ \\
\hline \multirow{2}{*}{$\begin{array}{l}\text { Prenatal supervisor support }(1=\text { strongly } \\
\text { disagree to } 4=\text { strongly agree) }\end{array}$} & $0.89(0.31)$ \\
\hline & No. (\%) \\
\hline \multicolumn{2}{|l|}{ Discrete } \\
\hline White & $615(86)$ \\
\hline Married & $531(74)$ \\
\hline College educated & $331(46)$ \\
\hline Primiparous & $333(47)$ \\
\hline Smoking during pregnancy & $97(14)$ \\
\hline Experienced prenatal mood disturbances & $333(47)$ \\
\hline One or more labor and delivery complications & $103(14)$ \\
\hline One or more chronic health problems & $116(16)$ \\
\hline Cesarean delivery & $123(17)$ \\
\hline Infant girl & $350(49)$ \\
\hline Colicky baby & $109(15)$ \\
\hline Some breastfeeding at 5-wk postpartum & $480(67)$ \\
\hline Very or somewhat satisfied with prenatal job & $637(89)$ \\
\hline \multicolumn{2}{|l|}{ Occupational classification } \\
\hline Service/blue collar & $103(14)$ \\
\hline Clerical & 281 (39) \\
\hline Professional & $158(47)$ \\
\hline $\begin{array}{l}\text { Employment status (back to work at } \\
5 \text {-wk postpartum) }\end{array}$ & $51(07)$ \\
\hline
\end{tabular}

no significant differences in time since childbirth to the interview between women who breastfed ( 33 days) and those who did not (34 days). Breastfeeding was more common among women on leave from work than those working, however (69\% vs $\left.37 \%, \chi^{2}=22, P<.001\right)$.

\section{DISCUSSION}

Women whose infants were delivered by cesarean section had significantly worse physical health than women who gave birth vaginally. Amidst the growing trend toward cesarean sections, parents and clinicians need to acknowledge the risks of operative deliveries. In this study, even in the absence of major surgical complica-
Table 4. Frequency of Specific Postpartum Symptoms $(n=716)$

\begin{tabular}{|c|c|}
\hline Symptoms & No. (\%) \\
\hline Fatigue & $457(63.8)$ \\
\hline Breast discomfort & $432(60.3)$ \\
\hline Decreased desire for sex & $375(52.4)$ \\
\hline Nipple irritation or soreness & $358(50.0)$ \\
\hline Headaches & $355(49.6)$ \\
\hline Back or neck pain & $310(43.3)$ \\
\hline Decreased appetite & $224(31.3)$ \\
\hline Constipation & $196(27.4)$ \\
\hline Runny or stuffy nose & $189(26.4)$ \\
\hline Hemorrhoids & $169(23.6)$ \\
\hline Excessive sweating & $165(23.0)$ \\
\hline Sore throat, cough, or cold & $164(22.9)$ \\
\hline $\begin{array}{l}\text { Abdominal pain including indigestion } \\
\text { (heartburn and cramps) }\end{array}$ & $149(20.8)$ \\
\hline Acne & $129(18.0)$ \\
\hline Dizziness & $104(14.5)$ \\
\hline Numbness or tingling of hands & $102(14.2)$ \\
\hline Hot flashes & $85(11.9)$ \\
\hline Sinus trouble & $84(11.7)$ \\
\hline Diarrhea or stomach flu & $54(7.5)$ \\
\hline Rash & $53(7.4)$ \\
\hline Fever $>100^{\circ} \mathrm{F}$ & $51(7.1)$ \\
\hline Breast infection/mastitis treated with antibiotics & $45(6.3)$ \\
\hline Asthma & $41(5.7)$ \\
\hline Hair loss & $34(5.0)$ \\
\hline Uterine infection treated with antibiotics & $19(2.7)$ \\
\hline Irregular heartbeats & $15(2.1)$ \\
\hline High blood pressure treated by a physician & $13(1.8)$ \\
\hline Bronchitis or pneumonia treated by a physician & $4(0.6)$ \\
\hline
\end{tabular}

tions, women who had undergone cesarean sections were not completely recovered after 5 weeks, which is just less than the 6-week period usually allotted for recovery from major surgery (eg, laparotomy for cholecystectomy). This finding is likely because these mothers were recovering from both childbirth and surgery and also had infant care responsibilities. These findings stress the importance of physicians educating women about the expected symptoms, duration of disability, and length of leave from work associated with delivery type.

Breastfeeding was associated with significantly more symptoms. While the physiological basis of these problems is not completely understood, it is likely that some symptoms, such as breast discomfort, relate to the physical process of breastfeeding. Increased fatigue may be due to the caloric expenditure of lactation, and excessive sweating and hot flashes may result from persistent hormonal changes. ${ }^{5}$ Constipation and hemorrhoids may relate to the women's hydration in association with breastfeeding. The decreased desire for sex among breastfeeding mothers is consistent with others' findings ${ }^{20}$ and may be based on hormonal changes or 


\begin{tabular}{|c|c|c|c|}
\hline \multirow[b]{2}{*}{ Independent Variables } & \multicolumn{3}{|c|}{ 2SLS Coefficients ( $P$ Value) } \\
\hline & Physical Health*1 & Mental Health ${ }^{\dagger}$ & Symptoms \\
\hline Preconception overall health (scaled 1 to 4 ) & $2.35(<.001)^{\ddagger}$ & $0.79(.04)^{\ddagger}$ & $-0.69(<.001)^{\ddagger}$ \\
\hline Prenatal moods ( 1 = yes) & $0.10(.86)$ & $-3.67(<.001)^{\ddagger}$ & $1.19(<.001)^{\ddagger}$ \\
\hline Cesarean delivery $(1=$ yes $)$ & $-5.96(<.001)^{\ddagger}$ & $0.60(.45)$ & $-0.19(.59)$ \\
\hline Infant sex ( 1 = female) & $-0.24(.64)$ & $-2.27(<.001)^{\ddagger}$ & $-.03(.91)$ \\
\hline Perceived control (scaled 1 to 4) & $0.83(.03)^{\ddagger}$ & $0.84(.06)^{\ddagger}$ & $-0.23(.27)$ \\
\hline Social support (scaled 5 to 25 ) & $0.06(.42)$ & $0.49(<.001)^{\ddagger}$ & $-0.03(.42)$ \\
\hline Breastfeeding ( 1 = yes) & $-1.32(.67)$ & $-1.49(.68)$ & $4.63(.00)^{\ddagger}$ \\
\hline Infant colic (1 = yes) & $0.69(.39)$ & $-1.25(.17)$ & $0.89(.04)$ \\
\hline Time elapsed since childbirth, $d$ & $0.14(.03)^{\ddagger}$ & $.02(.77)$ & $-.02(.44)$ \\
\hline \multicolumn{4}{|l|}{$2 \mathrm{SLS}=2$-stage least squares. } \\
\hline \multicolumn{4}{|c|}{$\begin{array}{l}\text { * Physical health was measured with the PCS (physical component summary of the SF-12) score. } \\
\text { † Mental health was measured with the MCS (mental component summary of the SF-12) score. } \\
\text { ₹ Statistically significant } t \text { test on the estimated 2SLS regression coefficient. }\end{array}$} \\
\hline
\end{tabular}

\section{Table 6. Significant Differences in Postpartum Symptoms by Women's Breastfeeding Status}

\begin{tabular}{|c|c|c|c|}
\hline Postpartum Symptoms & $\begin{array}{c}\text { Breastfeeding } \\
\text { No. }(\%) \\
(n=480)\end{array}$ & $\begin{array}{c}\text { Not Breastfeeding } \\
\text { No. }(\%) \\
(n=236)\end{array}$ & $\begin{array}{l}P \text { Value of } \\
t \text { Test or } \chi^{2}\end{array}$ \\
\hline \multicolumn{4}{|l|}{ Continuous variables* } \\
\hline Mean number of total symptoms & 6.6 & 5.1 & $<.001$ \\
\hline Mean number of nonbreastfeeding symptoms & 5.2 & 4.5 & .003 \\
\hline \multicolumn{4}{|l|}{ Discrete variables ${ }^{\dagger}$} \\
\hline $\begin{array}{l}\text { One or more breast symptoms (discomfort, } \\
\text { nipple soreness, infection) }\end{array}$ & $377(78.0)$ & $115(48.7)$ & $<.001$ \\
\hline Fatigue & $323(67.3)$ & $134(56.8)$ & .006 \\
\hline Decreased desire for sex & $284(59.2)$ & $91(38.6)$ & $<.001$ \\
\hline Back or neck pain & $223(46.5)$ & $87(36.9)$ & .015 \\
\hline Constipation & $152(31.7)$ & $44(18.6)$ & $<.001$ \\
\hline Hemorrhoids & $134(27.9)$ & $35(14.8)$ & $<.001$ \\
\hline Excessive sweating & $126(26.3)$ & $39(16.5)$ & .004 \\
\hline Hot flashes & $67(14.0)$ & $18(7.6)$ & .008 \\
\hline Decreased appetite & $136(28.3)$ & $88(37.3)$ & .020 \\
\hline Runny/stuffy nose & $115(24.0)$ & $74(31.4)$ & .040 \\
\hline
\end{tabular}

fatigue. The measure of breastfeeding used was relatively simplistic, and future studies are needed to validate these findings. If valid, findings suggest a role for physicians in counseling breastfeeding mothers about what to expect and how to manage symptoms.

Consistent with other studies, these mothers continued to experience several childbirth-related symptoms at 5 weeks postpartum, indicating a need for ongoing rest and recovery. ${ }^{5,7,8}$ Fatigue was the most frequent symptom, and $50 \%$ reported never or rarely feeling refreshed after waking in the morning. Although fatigue often results from reduced sleep and increased childcare responsibilities, it may also be related to low levels of hemoglobin. ${ }^{9}$
Some mothers may adapt better to their return to work by using an intermittent rather than straight-time family and medical leave. Intermittent leave under the federal Family and Medical Leave Act (FMLA) allows return to work on a gradual, part-time basis for a longer period of time. Women who struggle with fatigue or postpartum symptoms that limit daily role function may find intermittent leave helpful. Physicians, however, must certify intermittent leave as necessary for the mother's serious health condition (as defined in the FMLA regulations $)^{47}$ related to childbirth and distinct from time for infant bonding.

While study findings are internally valid, they can 
be generalized only to employed women of comparable demographic and income levels. Longitudinal studies are needed to examine which factors may affect women's health throughout the first postpartum year.

These mothers continued to experience several childbirth-related symptoms 5 weeks after delivery, indicating a need for rest and recovery beyond the traditional postpartum period. Physicians evaluating women during pregnancy and the postpartum may want to discuss strategies to promote health, expected symptoms, and duration of disability in relation to delivery type to promote maternal well-being. Postpartum evaluations should include an assessment of fatigue, the most common postpartum symptom, as well as other physical and mental symptoms, including those related to breastfeeding. Physicians should also discuss with mothers their plans to return to work and possible need for medical certification for FMLA, including intermittent leave.

To read or post commentaries in response to this article, see it online at http://www.annfammed.org/cgi/content/full/4/2/159.

Submitted July 12, 2005; submitted revised October 14, 2005; accepted November 9, 2005.

Key words: Postpartum period; postnatal care; maternal welfare; women's health; occupational health

Parts of this study were previously presented in the following formats: "The Health of Employed Women at 6 Weeks after Childbirth," P. McGovern, with B. Dowd, D. Gjerdingen, S. Kenney, L. Ukestad, D. McCaffrey, U. Lundberg, a poster presentation at the Academy Health Annual Research Meeting, 2005, Hynes Convention Center, Boston, Mass, June 27-28, 2005.

"Preliminary Findings from the Minnesota Postpartum Health Study: Women's Health 6 Weeks after Childbirth," P. McGovern with B. Dowd, D. Gjerdingen, T. Rockwood, C. Gross, S. Kenney, L. Ukestad, D. McCaffrey, U. Lundberg, After Birth: Policies for Healthy Women, Families, and Workplaces. A Signature Study and Conference of the Humphrey Institute of Public Affairs conducted in collaboration with the School of Public Health and Consortium on Law and Values in Health, Environment, and the Life Sciences Colloquia Program, Humphrey Institute of Public Affairs, University of Minnesota, Minneapolis, October 1, 2004.

"The Health of Employed Women at 6 Weeks after Childbirth: Preliminary Findings," P. McGovern with B. Dowd, D. Gjerdingen, T. Rockwood, C. Gross, S. Kenney, L. Ukestad, D. McCaffrey, U. Lundberg, at the Women's Health Research Conference, National Center for Excellence in Women's Health, University of Minnesota, Minneapolis, September 13, 2004.

"The Health of Employed Women at 6 Weeks after Childbirth: Preliminary Findings, " P. McGovern with B. Dowd, D. Gjerdingen, T. Rockwood, C. Gross, S. Kenney, L. Ukestad, D. McCaffrey, U. Lundberg, at the National Occupational Research Agenda (NORA) Symposium: Health and Safety Priorities for the 21st Century, Midwest Center for Occupational Health and Safety, University of Minnesota, Minneapolis, May 27, 2004.

"The Minnesota Women's Postpartum Health Study: Design, Implementation and Preliminary Findings," P. McGovern with B. Dowd, D. Gjerdingen, T. Rockwood, C. Gross, L. Ukestad, D. McCaffrey, U. Lundberg, at the School of Social Work, Wayne State University, Detroit, Mich, June 9, 2004.
Funding support: This publication was supported by grant \# 5 R18 OH003605-05 from the National Institute for Occupational Safety and Health (NIOSH).

Disclaimer: The contents of this study are solely the responsibility of the authors and do not necessarily represent the official views of NIOSH.

\section{References}

1. Labor force participation of mothers with infants in 2003. Washington, DC: US Bureau of Labor Force Statistics; 2004. Available at: http://www.bls.gov/opub/ted/apr/wk3/arto4.htm. Accessed: October $13,2004$.

2. US Census Bureau. Fertility of American women: June 2000, 2001. Available at: http://www.census.gov/prod/2001 pubs/p20-543rv.pdf. Accessed: March 2003, 2003.

3. Hayghe H. Developments in women's labor force participation. Mon Labor Rev. 1997:120:41-46.

4. Smith K, Downs B, O'Connell M. Maternity Leave and Employment Patterns: 1961-1995. Washington DC: U.S. Census Bureau; 2001.

5. Gjerdingen DK, Froberg DG, Chaloner KM, McGovern PM. Changes in women's physical health during the first postpartum year. Arch Fam Med. 1993;2:277-283.

6. McGovern P, Dowd B, Gjerdingen D, et al. Time off work and the postpartum health of employed women. Med Care. 1997;35:507-521.

7. Brown S, Lumley J. Maternal health after childbirth: results of an Australian population based survey. Br J Obstet Gynaecol. 1998; 105:156-161.

8. Killien MG, Habermann B, Jarrett M. Influence of employment characteristics on postpartum mothers' health. Women Health. 2001;33:63-81.

9. Lee KA, Zaffke ME. Longitudinal changes in fatigue and energy during pregnancy and the postpartum period. J Obstet Gynecol Neonatal Nurs. 1999;28:183-191

10. Thompson JF, Roberts CL, Currie M, Ellwood DA. Prevalence and per sistence of health problems after childbirth: associations with parity and method of birth. Birth. 2002;29:83-94.

11. Gjerdingen DK, Chaloner KM. The relationship of women's postpartum mental health to employment, childbirth, and social support. J Fam Pract. 1994;38:465-472.

12. O'Hara M, Swain A. Rates and risk of postpartum: a meta-analysis. Intl Rev Psychiatry. 1996;8:37-54.

13. Peindl KS, Wisner $\mathrm{KL}$, Hanusa $\mathrm{BH}$. Identifying depression in the first postpartum year: guidelines for office-based screening and referral. J Affect Disord. 2004;80:37-44.

14. United States Department of Health and Human Services, Office on Women's Health. Postpartum Depression. Washington DC: Office on Women's Health; 2001 June:1-2.

15. Tulman L, Fawcett J, Groblewski L, Silverman L. Changes in functional status after childbirth. Nurs Res. 1990;39:70-75.

16. Hamilton B, Martin J, Sutton P. Births: Preliminary data for 2002 Atlanta, Ga: Centers for Disease Control and Prevention; 2003.

17. Evidence Report. Vaginal Birth After Cesarean-section (VBAC). Washington DC: Agency for Healthcare Research and Quality (AHRQ). US Department of Health and Human Services; 2003. Technology Assessment Number 71.

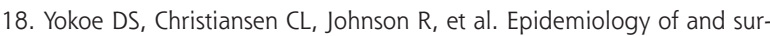
veillance for postpartum infections. Emerg Infect Dis. 2001;7:837-841.

19. Lydon-Rochelle M, Holt VL, Martin DP, Easterling TR. Association between method of delivery and maternal rehospitalization. JAMA. 2000;283:2411-2416.

20. Byrd JE, Hyde JS, DeLamater JD, Plant EA. Sexuality during pregnancy and the year postpartum. J Fam Pract. 1998;47:305-308. 
21. Hall W, McCracken K, Osterweil P, Guise JM. Frequency and predictors for postpartum fecal incontinence. Am J Obstet Gynecol. 2003; 188:1205-1207.

22. Rortveit G, Daltveit AK, Hannestad YS, Hunskaar S. Urinary incontinence after vaginal delivery or cesarean section. $N$ Engl J Med. 2003;348:900-907.

23. Healthy People 2010: Volume II. 2nd ed. Washington, DC: US Department of Health and Human Services; 2000. Available at: http://www.healthypeople.gov/ document/html/ objectives/16-19.htm. Accessed: 14 September 2005.

24. Li R, Darling N, Maurice E, Barker L, Grummer-Strawn LM. Breastfeeding rates in the United States by characteristics of the child, mother, or family: the 2002 National Immunization Survey. Pediatrics. 2005;115:e31-37.

25. Gartner LM, Morton J, Lawrence RA, et al. Breastfeeding and the use of human milk. Pediatrics. 2005;115:496-506.

26. American Academy of Family Physicians. Breastfeeding (Position Paper). 2001. Available at: http://www.aafp.org/x6633?xml.printxml. Accessed: 14 September, 2005.

27. Medline Plus. Medical Encyclopedia: Overcoming breastfeeding problems. 2004. Available at: www.nlm.nih.gov/ medlineplus/ency/ article/ http://002452.htm. Accessed: 14 September, 2005.

28. Barbosa-Cesnik C, Schwartz K, Foxman B. Lactation mastitis. JAMA. 2003;289:1609-1612.

29. Fein SB, Roe B. The effect of work status on initiation and duration of breast-feeding. Am J Public Health. 1998;88:1042-1046.

30. American College of Physicians. Breast-feeding education and support. 2000. Available at: http://www.acponline.org/ journals/ecp/ mayjun00/deshpande.htm. Accessed: 14 September, 2005.

31. Becker G. A theory of the allocation of time. Econ J. 1965;75:493517.

32. Grossman M. The Demand for Health: a Theoretical and Empirical Investigation. New York, NY: Columbia University Press: National Bureau of Economic Research; 1972. Occasional Paper 119.

33. Ware J, Kosinski M, Turner-Bowker D, Gandek B. Version 2 of the SF12 Health Survey. Lincoln, RI: QualityMetric Inc; 2002:3-7, 89,159.

34. Overview of Race and Hispanic Origin Census 2000 (C2KBR/01-1). Washington DC: US Dept. of Commerce, US Census Bureau; 2001.
35. Educational Differences in Health Status and Health Care. Data from the National Health Interview Survey, US, 1989. Vital and Health Statistics. Series 10, No 179. Washington DC, US GPO: National Center for Health Statistics; 1991. DHHS Pub. NO (PHS) 91-1507.

36. Palermo J. Health Information Data Dictionary Reference Guide to Natality Database. Minneapolis, Minn: Center for Health Statistics; 1997:1-88.

37. Mardburg B, Lundberg U, Frankenhaeuser M. The Total Workload of male and female white collar workers: construction of a questionnaire and a scoring system. Reports from the Department of Psychology. Stockholm, Sweden: Stockholm University; 1990. No. 714.

38. Sherbourne CD, Stewart AL. The MOS social support survey. Soc Sci Med. 1991;32:705-714.

39. Feldman R, Dowd B, Finch M, Cassou S. Employer-Based Health Insurance. National Center for Health Services Research and Health Care Technology Assessment. Rockville, Md: US Department of Health and Human Services; 1989. DHHS Pub. No. (PHS) 89-3434.

40. Cantor D, Waldfogel J, Kerwin J, et al. Balancing the Needs of Families and Employers: Family and Medical Leave Surveys. Washington DC: United States Department of Labor; 2001

41. Alphabetical Index of Industries and Occupations, 1990. Census of Population and Housing. Washington, DC: US Department of Commerce, Bureau of the US Census; 1992.

42. Quinn R, Staines G. The 1977 Quality Employment Survey. Ann Arbor, Mich: Survey Research Center, Institute for Social Research, University of Michigan; 1979.

43. Bond J, Galinsky E, Lord M, Staines G, Brown K. Beyond the Parental Leave Debate: The Impact of Laws in Four States. New York, NY: Family and Work Institute; 1991.

44. Kennedy P. A Guide to Econometrics. 5th ed. Cambridge, Mass: MIT Press; 2003:188-189.

45. Martin J, Hamilton B, Ventura S, et al. Births: Final Data for 2001. National Vital Statistics Report. Hyattsville, Md: National Center for Health Statistics; 2002.

46. National Center for Health Statistics. Births, Percentages of births by race, 2000-2002. PeriStats. 2005. Available at: http://www.marchofdimes.com/ peristats. Accessed: 14 September, 2005.

47. The Family and Medical Leave Act of 1993. 29 CFR; 1993. 